\title{
Farmacotherapieoverleg (FTO) in de huisartsopleiding
}

\author{
M.J.P. Ballieux, L.Wigersma
}

\section{Samenvatting}

Verslag wordt gedaan van de implementatie van een FarmacoTherapieOverleg (FTO) in het laatste jaar van de huisartsopleiding aan het Academisch Medisch Centrum (AMC). Het FTO vindt plaats tijdens de wekelijkse terugkomdagen van de huisartsen-in-opleiding (haio's). Aan de vaste groepen van haio's zijn gedurende een aantal bijeenkomsten apothekers in de registratiefase toegevoegd. Analoog aan het FTO voor reeds gevestigde huisartsen worden door deze groepen farmacotherapeutische onderwerpen behandeld. Het programma is opgezet in samenwerking met de Stichting Doelmatige Geneesmiddelenvoorziening $(D G V)$, die schriftelijk materiaal levert en de introductiebijeenkomsten leidt, en de Koninklijke Nederlandse Maatschappij ter bevordering der Pharmacie (KNMP), die zorgt voor de werving van apothekers. Het programma is gestart in 1996 en is inmiddels door twee cohorten haio's geëvalueerd. Beide cohorten oordelen positief. Het feit dat de haio's zelf inhoud en vorm kunnen geven aan dit programma wordt zeer gewaardeerd en lijkt een goede voorbereiding op de verdere huisartsenloopbaan.

\section{Inleiding}

Het maandelijkse FarmacoTherapieOverleg (FTO) van huisartsen en apothekers wordt zowel door de overheid als door de beroepsgroepen gezien als een belangrijk instrument bij het doelmatig voorschrijven van geneesmiddelen. Het wordt zelfs ten voorbeeld gesteld voor kwaliteits- en doelmatigheidsbeleid in de tweede lijn: een transmuraal FTO. 1

Sinds twee jaar is in het derde (laatste) jaar van de huisartsopleiding aan het Academisch Medisch Centrum - Universiteit van Amsterdam een FTO opgenomen in het kader van het onderwijs in deskundigheids- en kwaliteitsbevordering. Dit FTO is analoog opgezet aan het verplichte FTO voor geregistreerde huisartsen, waarin een huisartsengroep regelmatig thematische besprekingen heeft met een apotheker.

Tijdens dit programma kunnen de aspirant-huisartsen ervaring opdoen met FTO, contacten met apothekers leggen en het eigen medicatiebeleid op een aantal onderwerpen verbeteren. Het programma is gepland in het derde jaar van de opleiding. In dit artikel worden opzet en evaluatie van dit onderwijsprogramma besproken.

\section{Opzet van het onderwijs}

Het programma FTO voor het afdelingsonderwijs is ontwikkeld in samenwerking met de Stichting Doelmatige Geneesmiddelenvoorziening (DGV) en de Koninklijke Nederlandse Maatschappij ter bevordering der Pharmacie (KNMP). De Stichting DGV verzorgt de introductiebijeenkomst van dit onderwijsprogramma en levert ondersteunend schriftelijk materiaal. De KNMP zorgt voor de werving van apothekers. Dit betreft apothekers in de registratiefase, die nog niet zelfstandig gevestigd zijn. De positie en de ervaring van deze beroepsgroep en die van de haio's is dus enigszins vergelijkbaar.

Het FTO vindt plaats tijdens de terugkomdagen op de afdeling huisartsoplei- 
ding in het derde jaar. In de loop van dit jaar zijn er regelmatig bijeenkomsten waarbij één of twee apothekers toegevoegd zijn aan de vaste groepen haio's. Tijdens de introductiebijeenkomst worden de doelstellingen van het FTO besproken en wordt een planning gemaakt voor de vervolgbijeenkomsten. Elke groep bepaalt zelf de keuze van de onderwerpen en de gebruikte leermethoden.

De vervolgbijeenkomsten worden telkens door twee haio's en een apotheker voorbereid. Zij besteden hier per keer ieder twee uur aan. De drie voorbereiders hebben ook de leiding van de betreffende bijeenkomst: er is een inleider, een voorzitter en een notulist. Zo zijn in het jaar 1997/1998 door een van de groepen de volgende onderwerpen behandeld: dyslipidemie, eczeem, osteoporose/overgang, astma/COPD, polyfarmacie bij ouderen en diabetes mellitus type 2 . Als leermethoden zijn de deskundigheidsbevorderingpakketten en de DGV-voorbereidingsboekjes gebruikt, indien deze voor de betreffende onderwerpen voorhanden waren. Hierin staan kennistoetsen, casuïstiek en voorbeeldvoorschrijfcijfers. De DGV-voorbereidingsboekjes worden op verzoek toegestuurd door de DGV. De standaarden van het Nederlands Huisartsen Genootschap (NHG) en het 'Farmacotherapeutisch kompas' dienen als achtergrond en naslagwerk. Aan het eind van iedere bijeenkomst vindt een korte nabespreking plaats waarin de inhoud en de gang van zaken aan de orde komen. Van alle bijeenkomsten worden verslagen gemaakt, die aan alle deelnemers worden uitgedeeld. De huisarts-docent van de groep is tijdens twee bijeenkomsten aanwezig om te evalueren en zo nodig bij te sturen.

$\mathrm{Na}$ het eerste jaar van het FTO-programma is een aantal aanpassingen gedaan. Ten eerste is ervoor gekozen om niet één maar twee apothekers toe te voe- gen aan een groep haio's ter verbetering van de continuïteit. Ten tweede is het aantal bijeenkomsten uitgebreid van zes naar acht. Ten derde is naar aanleiding van een bij het eerste cohort geconstateerd ontbreken van eigen voorschrijfcijfers, voor het cohort 1997/1998 tijdens de tweede bijeenkomst aandacht besteed aan het algemeen gebruik van voorschrijfcijfers. Er is uitgelegd hoe men aan voorschrijfcijfers kan komen (via het eigen elektronisch medisch dossier, de apotheek of de ziekenfondsen) en hoe men ze kan toepassen. In de praktijk blijkt het echter vrijwel onmogelijk dat haio's over hun eigen voorschrijfcijfers kunnen beschikken: ze hebben vaak geen eigen inlogcode of de praktijk is nog niet geautomatiseerd.

\section{Evaluatie}

Het onderwijs in het derde jaar van de huisartsopleiding is de afgelopen twee jaar schriftelijk geëvalueerd halverwege het jaar. ${ }^{2}$ Door middel van een enquête onder 91 haio's zijn alle onderwijsprogramma's beoordeeld op een aantal algemene kenmerken en op factoren die invloed kunnen hebben op het leerresultaat. Dit maakt een evaluatie mogelijk van het FTO-onderwijs in 1996/1997 en 1997/ 1998.

De resultaten van deze schriftelijke evaluatie van het FTO-onderwijs door twee cohorten haio's zijn in tabel 1 en 2 weergegeven. De respons was 100\%. In de eerste tabel wordt een algemene beoordeling gegeven van het FTO-onderwijs, onderverdeeld in relevantie, bereikte voortgang en realiseerbaarheid van de gestelde leerdoelen. In de tweede tabel staan de scores die door de haio's zijn toegekend aan factoren die invloed hebben gehad op het leerresultaat. Alle vragen zijn beantwoord op een vijfpuntsschaal (--///+-/+/++). In de tabellen staan de percentages positieve $(+$ en ++ ) scores vermeld. 
Tabel 1. Algemene beoordeling van FTO: percentage positieve scores.

\begin{tabular}{lll}
\hline & $1996 / 1997$ & $1997 / 1998$ \\
& $\mathrm{~N}=46$ & $\mathrm{~N}=45$ \\
\hline Relevant voor toekomstig functioneren als huisarts & $89 \%$ & $96 \%$ \\
Beoordeling eigen voortgang & $57 \%$ & $87 \%$ \\
Eigen leerdoelen realiseerbaar & $62 \%$ & $91 \%$ \\
\hline
\end{tabular}

Tabel 2. Factoren die invloed hebben gehad op het leerresultaat: percentage positieve scores.

\begin{tabular}{|c|c|c|c|}
\hline & \multirow{2}{*}{$\begin{array}{l}1996 / 1997 \\
N=46\end{array}$} & \multirow{2}{*}{$\begin{array}{l}1997 / 1998 \\
N=45\end{array}$} \\
\hline & & & \\
\hline 1. & Inzet/deskundigheid apothekers & $65 \%$ & $91 \%$ \\
\hline 2. & Beschikbaarheid schriftelijk materiaal & $80 \%$ & $93 \%$ \\
\hline & Bijeenkomst over voorschrijfcijfers & n.v.t & $46 \%$ \\
\hline 4. & Inzet/voorbereiding mede-haio's & $85 \%$ & $91 \%$ \\
\hline & Aantal bijeenkomsten ( 6 in 96/97 en 8 in 97/98) & $72 \%$ & $95 \%$ \\
\hline 6. & Zelf voorbereiden van FTO & $89 \%$ & $96 \%$ \\
\hline
\end{tabular}

Beide tabellen tonen positieve scores zowel met betrekking tot de algemene kenmerken als met betrekking tot specifieke factoren die invloed hebben gehad op het leerresultaat. Het onderdeel over de voorschrijfcijfers van het FTO-onderwijs werd als matig beoordeeld. Het tweede cohort scoorde aanmerkelijk beter met name op de onderdelen beoordeling eigen voortgang, eigen leerdoelen realiseerbaar, inzet/deskundigheid apothekers en het aantal bijeenkomsten.

\section{Beschouwing}

Het FTO-programma is door de haio's goed beoordeeld. Opvallend is de positieve verschuiving van het eerste naar het tweede cohort. Deze positieve wending kan waarschijnlijk worden toegeschreven aan een verbetering van het programma zelf, bijvoorbeeld door de continue aan- wezigheid van de apothekers. Het inleidende programma over de voorschrijfcijfers is erg matig beoordeeld: de opzet was te theoretisch en sloot niet goed aan bij de behoeften en de kennis van de haio's. In het derde jaar (1998/1999) is daarom dit inleidende programma over voorschrijfcijfers minder theoretisch ingericht en is er een experiment opgestart om de haio's zelf voorschrijfcijfers bij te laten houden door het turven van medicatie bij een bepaald ziektebeeld.

Wij vinden dat het FTO-onderwijs een vaste plaats verdient in het curriculum voor het derde jaar van de huisartsopleiding. Er wordt overwogen om ook een FTO-programma in het eerste jaar in te passen in aanvulling op het bestaande farmacotherapieonderwijs. Dit eerstejaarsFTO zou gestructureerder van opzet moeten zijn, gezien de geringe ervaring 
van de huisartsen die net in opleiding zijn en de inhoud zou aan moeten sluiten bij de medische onderwerpen die in het eerste jaar behandeld worden.

De samenwerking met de apothekers blijft ook in het eerste jaar een belangrijk aspect van het FTO. Het is een van de weinige vormen van multiprofessioneel onderwijs: twee beroepsgroepen die samen een gemeenschappelijk onderwerp onder de loep nemen. Het gegeven dat beide groepen nog in opleiding zijn, maakt de drempel voor discussie en goede samenwerking lager.

Door de haio's zelf wordt, behalve de prettige samenwerking met de apothekers, zeer gewaardeerd dat ze zelf inhoud en vorm kunnen geven aan dit programma en men ziet het als een goede voorbereiding op de verdere huisartsenloopbaan.

\section{Literatuur}

1. Stuurgroep Kwaliteit en Doelmatigheid Farmaceutische Zorg Lange Termijn. Rapport van de commissie Koopmans. Rijswijk: Ministerie van VWS; 1998.

2. Ballieux MJP. Opzet en evaluatie van het nieuwe derdejaars programma in de huisartsopleiding AMC-UvA. In: Verweij AMJJ, Albersnagel EA, Cate ThJ ten, Denekens J, Dikkers JH, Remmen R, et al., redactie. Gezond Onderwijs-7. Houten/ Diegem: Bohn Stafleu Van Loghum; 1998. p. 31-2.

De auteur:

M.J.P. Ballieux, huisarts, Afdeling Huisartsgeneeskunde, divisie Public Health, Academisch Medisch Centrum/ Universiteit van Amsterdam.

Dr. L. Wigersma, hoofd huisartsopleiding, Afdeling Huisartsgeneeskunde, divisie Public Health, Academisch Medisch Centrum/Universiteit van Amsterdam.

Correspondentieadres:

Drs. M.J.P. Ballieux, Afdeling Huisartsgeneeskunde, divisie Public Health, Meibergdreef 151105 AZ Amsterdam, tel. 020-5667176, fax 020-6913548,

e-mail:m.ballieux@amc.uva.nl.

\section{Summary}

In this paper we report on the implementation and evaluation of pharmacotherapy meetings in the final year of the general practice vocational training programme of Amsterdam Academic Medical Center-University of Amsterdam. The meetings are held on the weekly education days of the general practitioners in training and are similar to the pharmacotherapy meetings for registered GPS. Pharmacist trainees join the regular groups of GP-trainees for discussions of pharmacotherapeutical subjects. The meetings started in 1996 and were evaluated by two year cohorts of GP trainees. Both groups gave a positive judgement. The fact that the GP trainees themselves determine content and format of the course is highly appreciated and seems a good preparation for their future careers in general practice. (Ballieux M.J.P., Wigersma L. Pharmacotherapy meetings in general practice vocational training. Dutch Journal of Medical Education 2000;19(3)102-105.) 